\title{
Eye contact and the perception of intelligence
}

\author{
R. WADE WHEELER, JOAN C. BARON, SUSAN MICHELL \\ and HARVEY J. GINSBURG \\ Southwest Texas State University, San Marcos, Texas 78666
}

\begin{abstract}
The perception of intelligence as a function of nonverbal cues was investigated in college students. Thirty undergraduate psychology majors estimated the GPAs of 20 upper division undergraduates based on their nonverbal behavior during a videotaped, career objectives interview. Significant relationships were found between estimated GPAs and two nonverbal behaviors: duration of eye contact and frequency of eye shifts. These nonverbal behaviors appear to be substantive mediators of the perception of an individual's intellectual facility during an interview.
\end{abstract}

The relationship between nonverbal cues and the perception of intelligence has been of interest to those who use such cues in evaluating an individual during an interview. Fear (1978) noted that the first 4 min of an interview typically determines its outcome; within this narrow time period, interviewers process and evaluate the potential of the person interviewed. The rapid nature of decision making on the part of an interviewer suggests that evaluative judgments are greatly influenced by the nonverbal style and characteristics of the interviewee, rather than actual verbal content of the message conveyed during dyadic interaction.

Eye contact has been viewed as a highly potent source of nonverbal communication. Cook (1977) found that eye contact or aversion was an important variable that regulates discourse between two individuals. It is apparently a major determinant of enhanced credibility and one of the first nonverbal cues noticed by an interviewer (Beebe, 1977). Several studies have attempted to document the relationship between eye contact and decision making during simulated employment situations. For example, Amalfitano and Kalt (1977) and Tankard (1970) found that photographs of perspective job applicants who exhibited greater eye contact toward a camera were rated higher as management trainees than applicants whose eyes averted the camera. Similarly, Imada and Hakel (1977) described a general nonverbal constellation involving eye contact, smiling, gestures, and attentive body posture that produced consistently favorable ratings by interviewers. They noted that when these nonverbal cues were present, the job applicant was characteristically described as a warm, enthusiastic, and likable person by raters and, as a result, recommended for the position.

Thus, eye contact may be a dominant nonverbal cue that suggests a positive emotional state. In addition to transmitting positive effect, eye contact may also

Reprints may be requested from $R$. Wade Wheeler, Department of Psychology, Southwest Texas State University, San Marcos, Texas 78666. mediate the perception of cognitive skills that would influence the interviewer's subjective rating of an interviewee's intellectual capacity. This study was performed in an attempt to determine the extent to which eye contact and a number of other nonverbal behaviors (smiling, head nods, arm gestures, eyebrow movement) influence the perception of intelligence (as indicated by estimates of academic grade point average, GPA) during a videotaped simulated personnel interview.

\section{METHOD}

\section{Subjects}

Thirty undergraduate psychology majors (18 female, 12 male) enrolled in an experimental psychology course participated in the experiment.

\section{Apparatus}

A black-and-white videotape of 20 upper division undergraduates who were interviewed about career objectives was used as a media stimulus in this study. A well trained, female interviewer elicited information from the interviewees. A hidden video camera was positioned directly behind the interviewer. During the interview, the camera recorded a 2-min facial close-up and a 2-min upper body recording (all participants were seated) for each individual. It should be noted that the camera angle and position were situated to allow a maximum correspondence between camera and face of interviewer. Thus, the videotaped record provided an extremely close approximation of the visual reference frame of the interviewer. Males and females were equally represented and were randomly distributed throughout the videotape presentation.

Prior to the experiment, permission was obtained from each individual to use the tape of his or her interview. Permission was also obtained for the release of transcripts and GPAs for later data analysis concerning accuracy of subject estimations of GPA based on the visual cues provided by the videotaped interview.

The videotape was edited so that a 30 -sec visually dark interval appeared between each 4-min interview segment. A 25-in. black-and-white television monitor was used to present the video record to subjects participating in the study.

Procedure

Each interviewee was scored by naive judges on a number of nonverbal dimensions: duration of eye contact with the 
Table 1

Spearman Correlation Coefficients (rho) and Associated p Values for Comparisons Between Estimated GPA and Categories of Nonverbal Behavior and Between Estimated and Actual GPA

\begin{tabular}{lcc}
\hline $\begin{array}{l}\text { Event Compared to } \\
\text { Perceived GPA }\end{array}$ & rho & $\mathrm{p}$ \\
\hline Actual GPA & +.31 & n.s. \\
Eye Contact & +.56 & .01 \\
Eye Shifts & -.44 & .05 \\
Eyebrow Movement & +.02 & n.s. \\
Head Nods (Yes) & -.17 & n.s. \\
Head Nods (No) & +.18 & n.s. \\
Hand Gestures & -.01 & n.s. \\
Smiling & +.28 & n.s. \\
\hline
\end{tabular}

interviewer during the 4-min presentation, frequency of eye movements away from interviewer (eye aversion), frequency of eyebrow movements (as an index of general facial animation), frequency of affirmative and negative head nods, frequency of arm gestures, and frequency of smiling.

The subjects of this study were presented the video portion of the recorded interview on the 25 -in. monitor (audio off). During the $30-\mathrm{sec}$ intertrial interval, subjects estimated the GPA of each interviewee based on the nonverbal cues provided by the video record.

\section{RESULTS}

The results are shown in Table 1. A Spearman rank-order correlation coefficient was used to determine the relationship between actual and average estimated GPAs and between an interviewee's average estimated GPA and several nonverbal behaviors (duration of eye contact, frequency of eye shifts, eyebrow movements, smiling, head nods, and arm gestures). There was no significant relationship between actual GPA and GPAs estimated by subjects viewing the silent videotape record of the interview $\left(r_{s}=.31\right)$. However, a highly significant relationship was found between estimated GPA and two nonverbal behaviors: duration of eye contact $\left(\mathrm{r}_{\mathrm{s}}=.56, \mathrm{p}<.01\right.$, one-tailed $)$ and frequency of eye shifts $\left(r_{s}=-.44, p \leqslant .05\right.$, one-tailed). No other measured nonverbal cue was correlated with the perception of an interviewee's GPA.

\section{DISCUSSION}

The data of this study suggest little relationship between an interviewee's actual GPA and the GPA perceived by subjects exposed to a silent 4-min videotape of each individual during an interview. However, the purpose of the study was to demonstrate the relationship between perceived GPA (as a measure of perceived intellectual ability) and a number of nonverbal behaviors. Duration of eye contact and frequency of eye movement or shifts were the only nonverbal behaviors demonstrating a statistically significant relationship to perceived GPA. Interviewees exhibiting longer durations of eye contact and fewer eye shifts were more likely to be rated as having a higher GPA than individuals who generally avoided eye contact and frequently averted their eyes during the interview.

A plausible explanation of the relationship between fewer eye movements and the perception of higher intelligence is suggested by Kendon's (1967) research on nonverbal regulators of verbal discourse. He noted that people tend to look away or shift their eyes from the person to whom they are talking if a hesitation occurs in their speech. Similarly, Hiscock (1975) reported that frequency of eye shifts were associated with perceived difficulty of the question asked, while Meskin (1974) found an increase in ocular shifting when people engaged in extended mental searches for answers to questions posed by interviewers. Perhaps fewer eye shifts are associated with efficient recognition or recall memory storage systems and are thus characteristically interpreted as some index of general intellectual ability by persons who view another individual being interviewed. In any event, eye contact in conjunction with relatively few eye shifts appear to be substantive mediators of the perception of an individual's intellectual facility during an interview.

\section{REFERENCES}

Amalfitano, G., \& Kalt, N. C. Effects of eye contact on evaluation of job applicants. Journal of Employment Counseling, 1977, 14, 46-48.

BEEBE, S. Effects of eye contact, posture, and vocal inflection upon comprehension and credibility. Dissertation Abstracts, University of Missouri, 1977, 37, 5436-5437.

Cook, M. Gaze and mutual gaze in social encounters. American Scientist, 1977, 65, 328.

FeAR, R. A. The evaluation interview (2nd ed.). New York: McGraw-Hill, 1978.

Hiscock, M. Some situational antecedents and dispositional correlates of lateral eye movement. Dissertation Abstracts, University of Texas, 1975, 36, 942.

IMADA, A. S., \& HAKEL, M. D. Influence of nonverbal communication and rater proximity on impressions and decision in simulated employment interviews. Journal of Applied Psychology, 1977, 62, 295-300.

KENDON, A. Some functions of gaze direction in social interaction. Acta Psychologica, 1967, 26, 1-47.

Meskin, B. B. Daydreaming, reflective thought and laterality of eye movements. Journal of Personality and Social Psychology, 1974, 30, 64-67.

TANKARD, J. W. Effects of eye position on person perception. Perceptual and Motor Skills, 1970, 31, 883-893.

(Received for publication November 29, 1978.) 